Article

\title{
Preliminary Characterization, Antioxidant Properties and Production of Chrysolaminarin from Marine Diatom Odontella aurita
}

\author{
Song Xia ${ }^{1,2, \dagger}$, Baoyan Gao ${ }^{1, \dagger}$, Aifen Li ${ }^{1}$, Jihai Xiong ${ }^{2}$, Ziqiang Ao ${ }^{2}$ and Chengwu Zhang ${ }^{1, *}$ \\ 1 Institute of Hydrobiology, Jinan University, Guangzhou 510632, China; \\ E-Mails: xiasongsummer212@163.com (S.X.); gaobaoyan1211@126.com (B.G.); \\ tiger@jnu.edu.cn (A.L.) \\ 2 Institute of Energy Research, Jiangxi Academy of Sciences, Nanchang 330096, China; \\ E-Mails: xjh6110@vip.sina.com (J.X.); aoziqiang628@163.com (Z.A.) \\ $\dagger$ These authors contributed equally to this work. \\ * Author to whom correspondence should be addressed; E-Mail: tzhangcw@jnu.edu.cn; \\ Tel./Fax: +86-20-85224366.
}

Received: 26 June 2014; in revised form: 9 September 2014 / Accepted: 9 September 2014 / Published: 23 September 2014

\begin{abstract}
A new chrysolaminarin, named CL2, with a molecular mass of $7.75 \mathrm{kDa}$, was purified from the marine diatom, Odontella aurita, using DEAE-52 cellulose anion-exchange chromatography and Sephadex G-200 gel-filtration chromatography. The monosaccharide and structural analysis revealed that CL2 was a glucan mainly composed of glucose, which was linked by the $\beta-\mathrm{D}-(1 \rightarrow 3)$ (main chain) and $\beta$-D- $(1 \rightarrow 6)$ (side chain) glycosidic bond, demonstrated by infrared spectroscopy (IR) and nuclear magnetic resonance (NMR). The antioxidant activity tests revealed that the CL2 presented stronger hydroxyl radical scavenging activity with increasing concentrations, but less was effective on reducing power analysis and scavenging 1,1-diphenyl-2-picrylhydrazyl (DPPH) radical. The influences of nitrogen concentration and light intensity on chrysolaminarin production of O. aurita were further investigated in a glass column photobioreactor, and a record high chrysolaminarin productivity of $306 \mathrm{mg} \mathrm{L}^{-1}$ day $^{-1}$ was achieved. In conclusion, the chrysolaminarin CL2 from $O$. aurita may be explored as a natural antioxidant agent for application in aquaculture, food and pharmaceutical areas.
\end{abstract}


Keywords: Odontella aurita; chrysolaminarin; structural characteristics; antioxidant activity; productivity

\section{Introduction}

Oxidative stress causes lots of damage to biological macromolecules, such as nucleic acids, proteins, lipids and carbohydrates, which may lead to the development of chronic and degenerative ailments [1]. Although a variety of synthetic chemicals, such as phenolic compounds, are found to be effective radical scavengers, they usually have side effects. Thus, many efforts have been spent on searching for compounds with antioxidant activity and low cytotoxicity from natural materials.

Recently, accumulated evidence has demonstrated that natural polysaccharides are effective antioxidants for scavenging reactive oxygen species (ROS) [2-4]. Marine diatoms accumulate $\beta$-D-1,3-glucans, also called chrysolaminarin, as an energy storage carbohydrate, especially upon nutrient-depletion conditions [5]. The chrysolaminarin from several diatoms have been characterized and found to be a $\beta-1,3$-glucan with a degree of polymerization (DP) in the range of 5-60 and a degree of branching (DB) of $0-0.2$ at Position 6 [6]. A large number of studies indicated that $\beta$-glucans obtained from various organisms, such as plants, algae and microorganisms, are effective agents in scavenging ROS, stimulating immunity in fish, as well as treating diseases, like cancer, infection, inflammation and influenza [7-10]. However, little attention has been devoted to the production and biological activities of chrysolaminarin from marine diatoms.

The marine diatom, Odontella aurita, has been industrially cultured in raceways and used as a dietary supplement rich in $\omega-3$ polyunsaturated fatty acids (PUFAs) for several years [11,12]. Some other bioactive compounds contained in this microalga, such as fucoxanthin and phytosterols, have been isolated, structurally elucidated and proved to be beneficial to human health [13-15]. No studies have been reported, to our knowledge, on the structural characteristics and bioactivities of chrysolaminarin in $O$. aurita. In this study, a new storage chrysolaminarin was purified from $O$. aurita. Its monosaccharide composition, chemical structure and antioxidant activity were characterized. The production of chrysolaminarin from $O$. aurita was also investigated in glass column photobioreactors. This research is aimed at characterizing the structure and antioxidant capacity of a new chrysolaminarin purified from the marine diatom, $O$. aurita, and evaluating its production potential in glass column photobioreactor.

\section{Results and Discussion}

\subsection{Isolation, Purification and Characterization of Chrysolaminarin}

\subsubsection{Purification and Homogeneity of Chrysolaminarin}

The crude polysaccharide was isolated from freeze-dried $O$. aurita and then chromatographed on a DEAE-52 cellulose column (Pharmacia, Uppsala, Sweden). After being gradient eluted with an aqueous solution of $\mathrm{NaCl}(0.1,0.3$ and $0.5 \mathrm{M})$, one major peak, named $\mathrm{CL} 1$, was obtained from the $0.1 \mathrm{M} \mathrm{NaCl}$ eluate (Figure 1). Next, the fraction CL1 was applied to Sephadex G-200 gel-filtration 
column chromatography (Pharmaci, Uppsala, Sweden) for further purification, yielding a single, symmetric and sharp peak, which indicated that the obtained polysaccharide, named CL2 (chrysolaminarin 2), was homogeneous (Figure 2). The UV spectrum showed no significant absorbance at $260 \mathrm{~nm}$ or $280 \mathrm{~nm}$, indicating that CL2 contained no protein or nucleic acid (data not shown).

Figure 1. DEAE-cellulose column elution profile of crude polysaccharide from $O$. aurita.

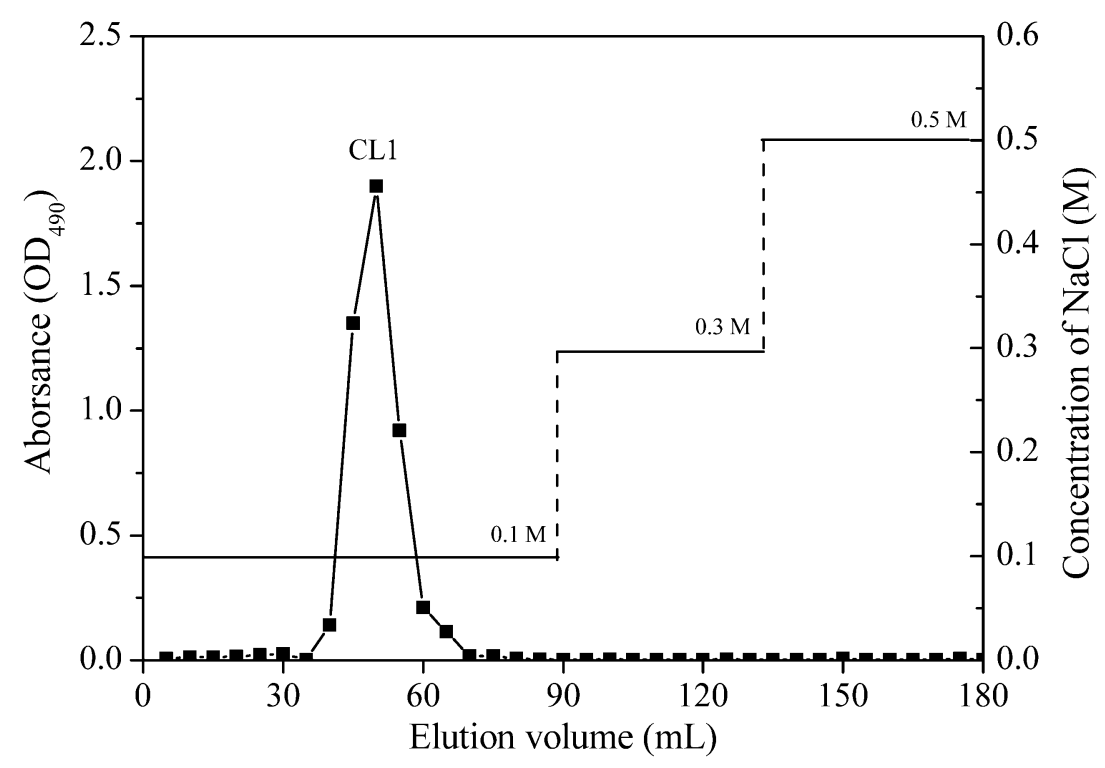

Figure 2. Sephadex G-200 gel-filtration chromatogram of the fraction CL1 (chrysolaminarin 1) obtained from DEAE-cellulose column elution.

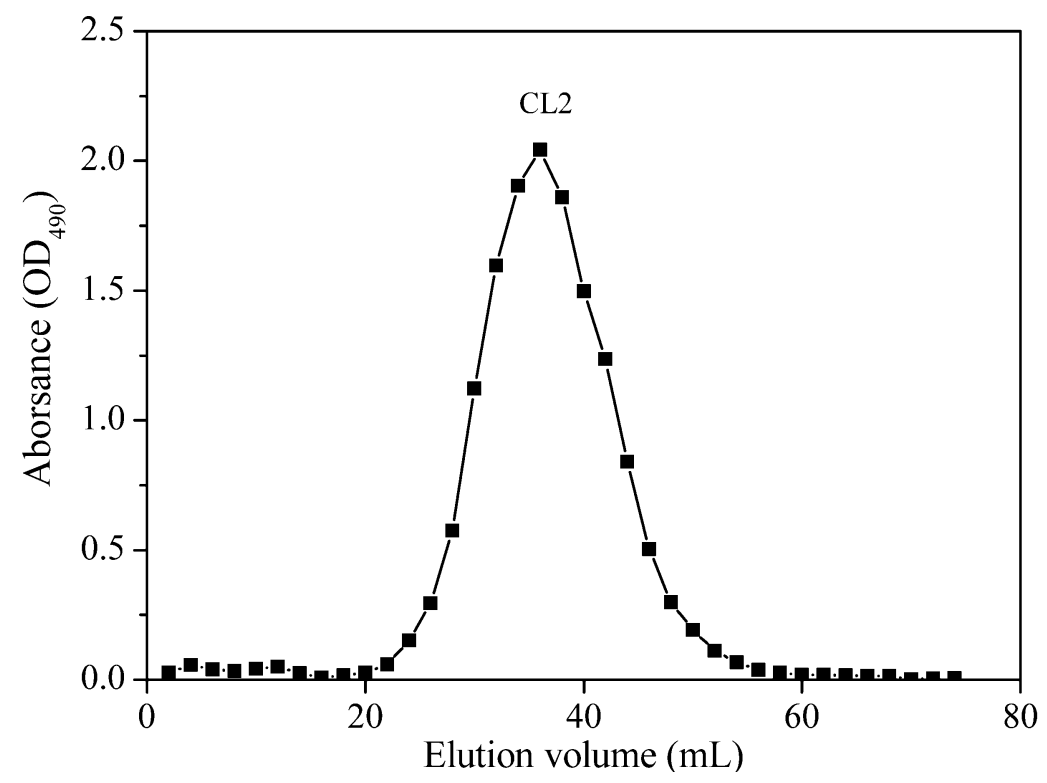

2.1.2. Monosaccharide Composition and Molecular Weight of CL2

Chrysolaminarins from various diatoms span a great number of different molecular weights, from $\sim 1$ to $40 \mathrm{kDa}$ [6]. The average molecular weight of CL2 was found to be $7.75 \mathrm{kDa}$ based on the results of gel-filtration chromatography. The monosaccharide composition of CL2 was analyzed by complete acid hydrolysis and the GC-MS analysis methods. The results shown in Table 1 indicate that the sugar 
components of CL2 are mainly composed of glucose $(82.23 \%)$ with smaller amounts of mannose $(13.27 \%)$ and traces of ribose, arabinose, xylose and galactose.

Table 1. Monosaccharide composition of CL2 from O. aurita.

\begin{tabular}{cccccc}
\hline \multicolumn{7}{c}{ Sugar Components (Total Sugar ${ }^{\text {a }}$ \%) } \\
\hline Glucose & Mannose & Ribose & Arabinose & Xylose & Galactose \\
\hline 82.23 & 13.27 & 0.46 & 3.62 & 0.26 & 0.16 \\
\hline \multicolumn{7}{c}{ a Total sugar: the sum of the six monosaccharides. }
\end{tabular}

\subsubsection{FTIR Spectra Analysis}

As shown in Figure 3, the FTIR spectra of CL2 showed a significant, strong broad characteristic peak at around $3431 \mathrm{~cm}^{-1}$, corresponding to the stretching vibration of $\mathrm{O}-\mathrm{H}$ groups, as well as a C-H band at $2923 \mathrm{~cm}^{-1}[16,17]$. Two prominent absorption bands between 1200 and $1000 \mathrm{~cm}^{-1}$ are dominated by ring vibrations overlapped with C-O glycosidic band vibration $[10,18,19]$. The stretching peak at $1639 \mathrm{~cm}^{-1}$ and a weak stretching peak appeared at $1377 \mathrm{~cm}^{-1}$ were due to the presence of carboxyl groups [20]. The characteristic peak of $\beta$-glycosidic linkage at $889 \mathrm{~cm}^{-1}$ demonstrated that the obtained polysaccharide CL2 was a $\beta$-type polysaccharide [20].

Figure 3. The FTIR spectra of CL2 from O. aurita.

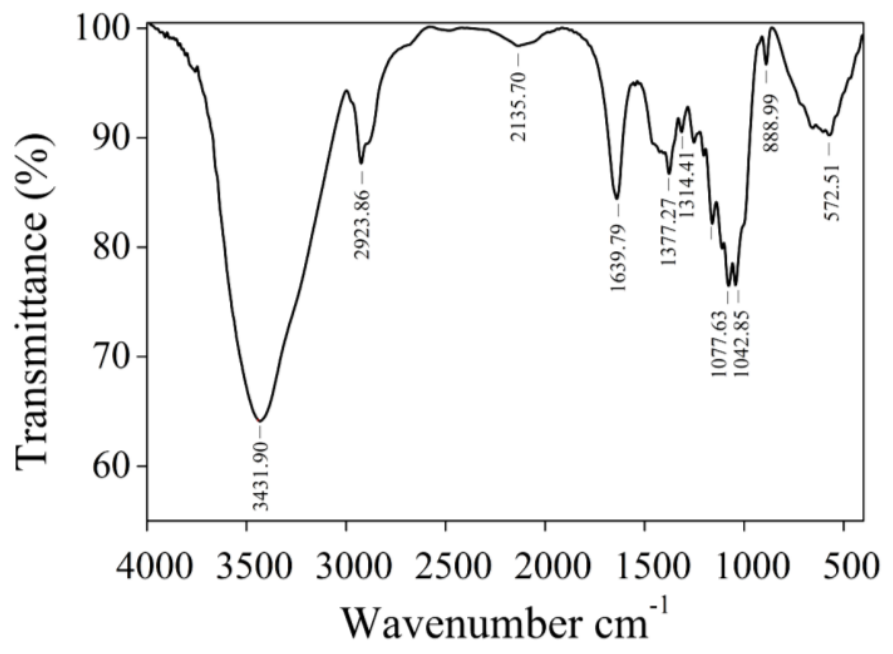

\subsubsection{NMR Spectra Analysis}

The ${ }^{1} \mathrm{H}-\mathrm{NMR}$ and ${ }^{13} \mathrm{C}-\mathrm{NMR}$ spectra of CL2 are presented in Figure 4. The anomeric proton single at $\delta 4.39$ and $4.08 \mathrm{ppm}$ in the ${ }^{1} \mathrm{H}$ NMR were assigned to $\mathrm{H}-1$ of the $\beta-1,3$-linkage and the $\beta$-1,6-linkage, respectively [21,22], which agree with the presence of an IR band at $889 \mathrm{~cm}^{-1}$. Based on the respective peak areas at 4.39 and $4.08 \mathrm{ppm}$ on the ${ }^{1} \mathrm{H}-\mathrm{NMR}$ spectrum, the ratio of the $\beta-1,3-$ to $\beta-1,6$-linkage was estimated to be $4: 1$. The ${ }^{13} \mathrm{C}-\mathrm{NMR}$ spectrum showed major signals at $\delta 104.2-104.6,86.5-87.3,78.1-78.4$, 77.6-78.1, 75.1-75.4, 71.5, 69.1-70.6 and 62.3-63.1 (Figure 4b). These signals are in agreement with the results from previous analysis of microalgae Chaetoceros muelleri and Pleurochrysis haptonemofera [21,23], which indicated that the CL2 obtained from $O$. aurita has a $\beta$-D- $(1 \rightarrow 3)$ (main chain) and $\beta$-D- $(1 \rightarrow 6)$ (branch chain)-linked glucopyranan structure. The integrated analysis of 
structural information demonstrated that the obtained polysaccharide CL2 from $O$. aurita is a medium molecular weight chrysolaminarin, mainly composed of a $\beta$-D- $(1 \rightarrow 3)$ - (main chain) and $\beta$-D- $(1 \rightarrow 6)$ (side chain)-linked glucose.

Figure 4. (a) ${ }^{1} \mathrm{H}-\mathrm{NMR}$ and (b) ${ }^{13} \mathrm{C}-\mathrm{NMR}$ spectrum of $\mathrm{CL} 2$ from $O$. aurita (NA: not assigned).

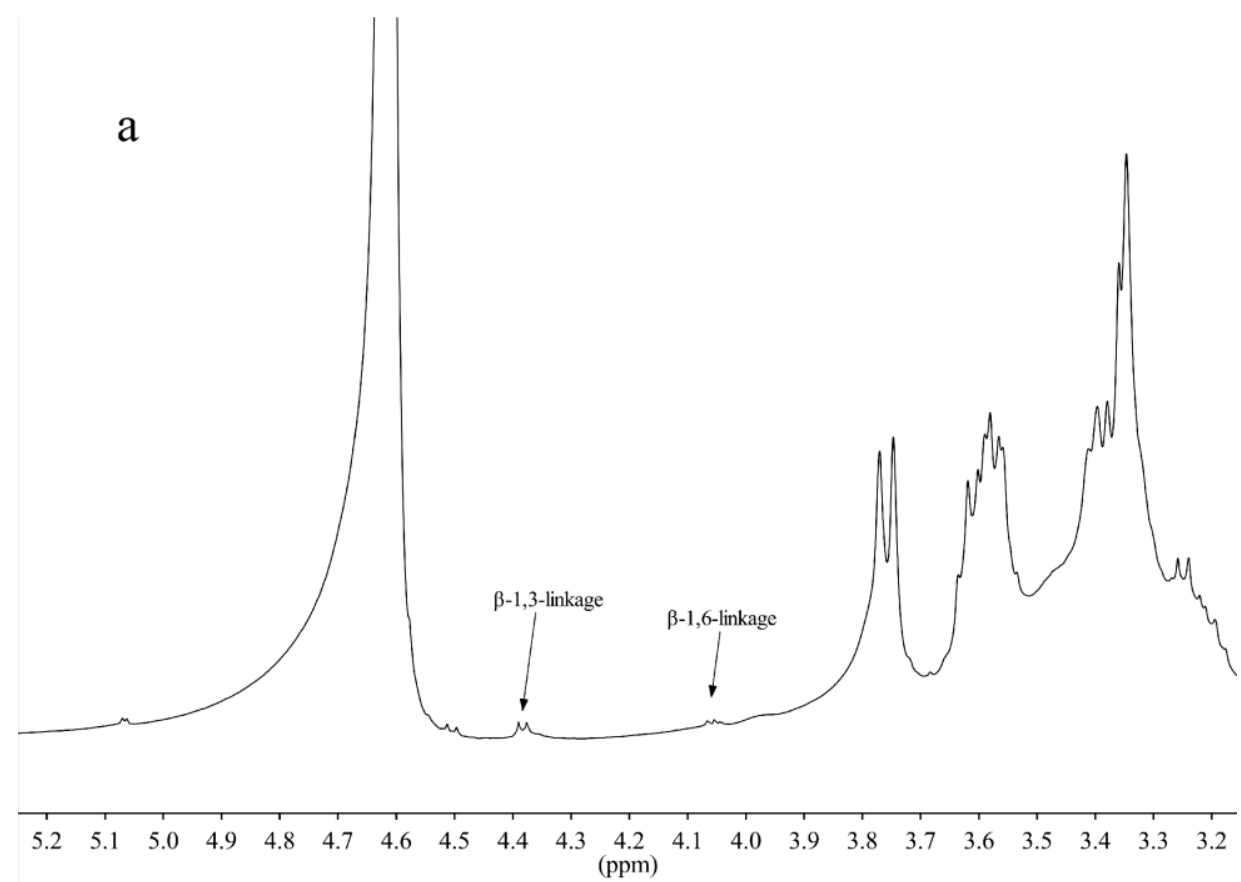

b

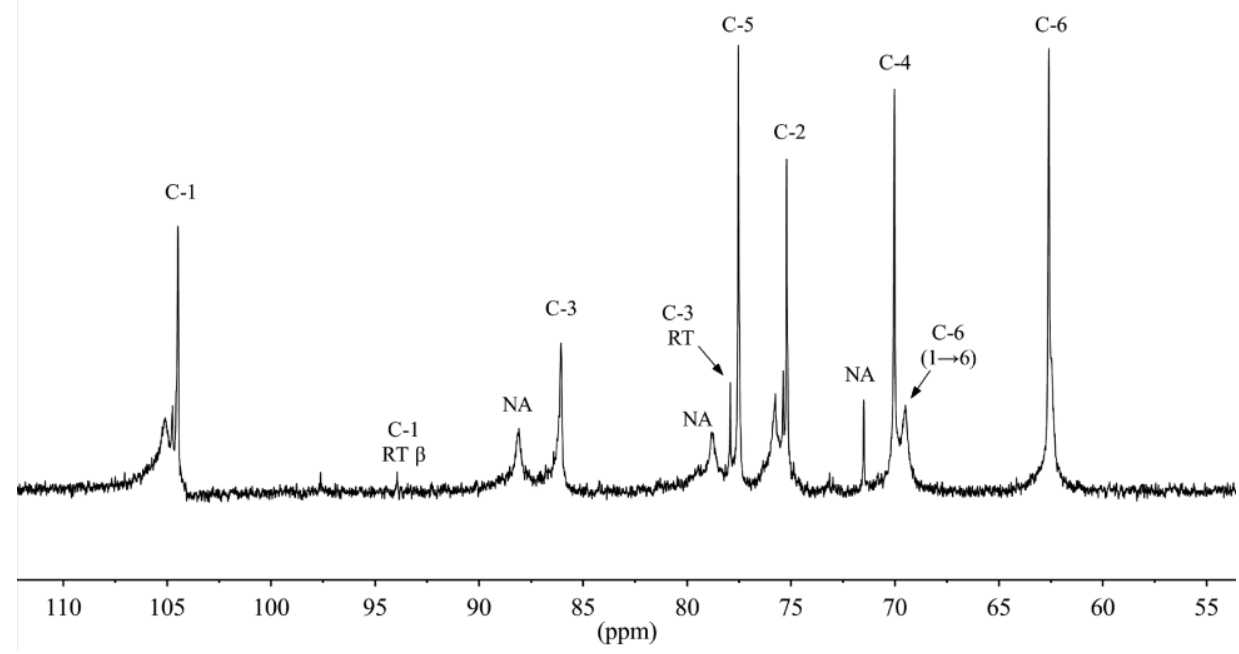

\subsection{Assay for Antioxidant Activity}

\subsubsection{Reducing Power}

For the assessment of the reducing power, the $\mathrm{Fe}^{3+}-\mathrm{Fe}^{2+}$ transformation of CL2 was investigated using the potassium ferricyanide reduction method (Figure 5a). The results revealed that the reducing power of CL2 was weak. At $2 \mathrm{mg} \mathrm{mL} \mathrm{m}^{-1}$, CL2 showed a reducing power of $0.046 \pm 0.015 \mathrm{abs}$, which 
gradually increased to $0.554 \pm 0.139$ abs at $100 \mathrm{mg} \mathrm{mL}^{-1}$; whereas the reducing power of ascorbic acid (VC) reached a plateau of $2.508 \pm 0.13$ abs at $2 \mathrm{mg} \mathrm{mL}^{-1}$. Kozarski et al. [24] declared that starch exhibited no reducing power in their study. Lo et al. [25] reported a weak relationship between reducing power and monosaccharide composition, and they also found that the reducing power of polysaccharides was much lower than that of ascorbic acid. Kanmani et al. [26] found that the exopolysaccharide from Streptococcus phocae exhibited a rather weak reducing power (0.2 abs at $2 \mathrm{mg} \mathrm{mL}{ }^{-1}$ ), which was much lower than that of ascorbic acid (reaching its plateau of 2.5 abs at $\left.0.4 \mathrm{mg} \mathrm{mL}^{-1}\right)$.

Figure 5. Antioxidant assays for the chrysolaminarin CL2 from O. aurita. (a) Reducing power; (b) scavenging of DPPH radicals; (c) scavenging of hydroxyl radicals. Values are the means $\pm \mathrm{SD}(n=3)$. When error bars cannot be seen, the error is less than the size of the symbol.

a

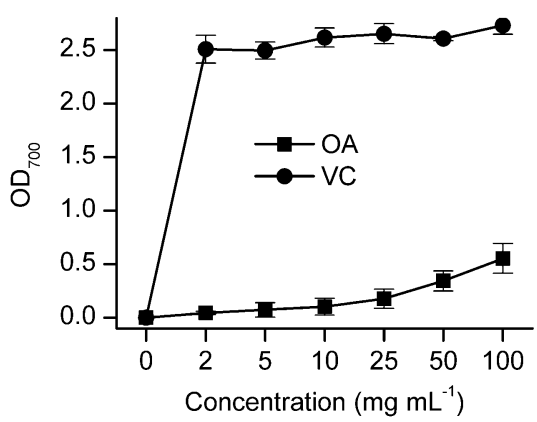

b

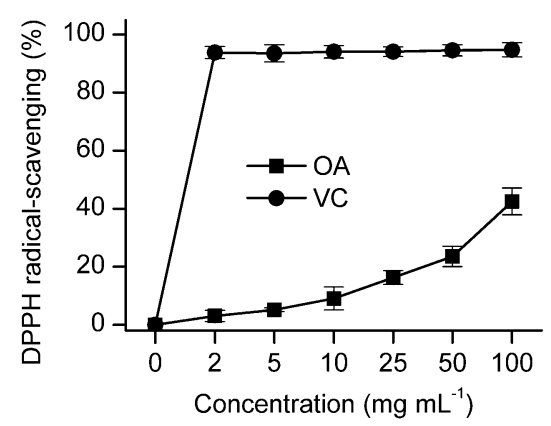

c

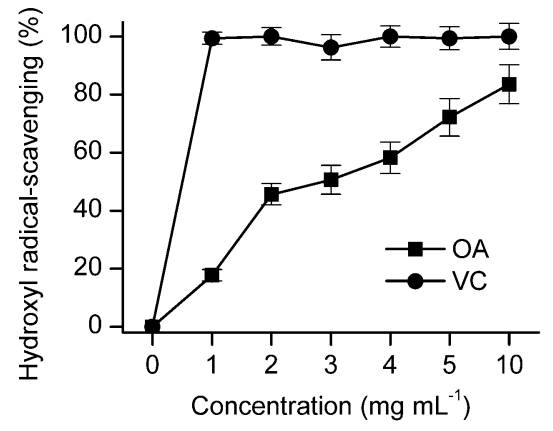

\subsubsection{DPPH Radical Scavenging Activity}

The DPPH free radical has been widely used as a tool to evaluate the antioxidant activity. The results shown in Figure $5 \mathrm{~b}$ indicated that the scavenging activity of CL2 increased slowly with the increase of dosage in a concentration-dependent manner. When the concentration of CL2 was at $100 \mathrm{mg} \mathrm{mL}^{-1}$, its scavenging activity reached $42.455 \% \pm 4.671 \%$. Ascorbic acid expressed a much higher scavenging ability and reached a plateau of $93.774 \% \pm 2.089 \%$ at $2 \mathrm{mg} \mathrm{mL}^{-1}$. The structural characteristics of polysaccharide, such as molecular weight, monosaccharide composition, availability of hydroxyl group and conformation of side chains, were reported to be responsible for the scavenging ability of polysaccharide [2,25,27].

\subsubsection{Hydroxyl Radical Scavenging Activity}

Hydroxyl radical is believed to be the most harmful free radical in the reactive oxygen species, as it could induce severe damage to adjacent biomolecules [28]. The hydroxyl radical scavenging activity of CL2 is shown in Figure 5c. The CL2 exhibited high scavenging activity on hydroxyl radical, and the scavenging effect of polysaccharide enhanced with increasing dosage. At $1 \mathrm{mg} \mathrm{mL}{ }^{-1}$, CL2 showed hydroxyl radical scavenging activity of $17.72 \% \pm 1.98 \%$, which gradually increased to $83.54 \% \pm 6.71 \%$ at $10 \mathrm{mg} \mathrm{mL}^{-1}$. However, the scavenging activity of CL2 was much lower than that of ascorbic acid, as it reached a plateau of $99.38 \% \pm 2.089 \%$ at $1 \mathrm{mg} \mathrm{mL}^{-1}$. The potential antioxidant activity of 
chrysolaminarin from $O$. aurita may lead to the development of a novel natural antioxidant agent. The results were in accord with Kanmani et al. [26], who found that the purified exopolysaccharide exhibited low reducing power, but relatively strong hydroxyl radical scavenging activity; at $1.2 \mathrm{mg} \mathrm{mL}$, the hydroxyl radical scavenging activity of purified exopolysaccharide reached almost $20 \%$, which increased to $40 \%-45 \%$ at $2.4 \mathrm{mg} \mathrm{mL}^{-1}$. In all experiments, the control ascorbic acid showed much better antioxidant activity than exopolysaccharide produced from $S$. phocae.

There are a number of reports on the evaluation of antioxidant activity in diatoms (Phaeodactylum tricornutum and Chaetoceros calcitrans) or other microalgae (Botryococcus braunii, Porphyridium cruentum and Scenedesmus obliquus) [29,30]. These studies concluded that several microalgal genera contain potent antioxidants. However, the experiments were carried out with lipophilic and hydrophilic extracts, not a purified compound. Kanmani et al. [26] also found that crude exopolysaccharide extract showed higher reducing power and hydroxyl radical scavenging activity than purified exopolysaccharide, which may be due to the antioxidant components, such as proteins, amino acids, organic acids and other microelements, in crude exopolysaccharide.

\subsection{Production of Chrysolaminarin from O. aurita in a Column Photobioreactor}

To investigate the accumulation pattern of chrysolaminarin in O. aurita, the biomass concentration and chrysolaminarin content of $O$. aurita cultivated in the glass column photobioreactor were studied (Figure 6). The biomass concentration of $O$. aurita had been illustrated in our previous paper [15], which concluded that high light intensity $\left(300 \mu \mathrm{mol}\right.$ photons $\left.\mathrm{m}^{-2} \mathrm{~s}^{-1}\right)$ and nitrogen-replete condition $(18 \mathrm{mM})$ were favorable to obtain high biomass accumulation, and the maximum biomass concentration of $6.36 \mathrm{~g} \mathrm{~L}^{-1}$ was achieved on Day 10 (Figure 6b). Under low light, the chrysolaminarin content in the low nitrogen cultures increased from $15.09 \%$ of dry weight (DW) to $61.34 \%$ DW during a 12-day cultivation. In the high nitrogen cultures, chrysolaminarin content remained stable in the first eight days and then gradually increased to $39.67 \% \mathrm{DW}$ at the end of the culture period (Figure 6c). Under high light, the changes in chrysolaminarin content followed the similar trends of their counterparts under low light with the difference being that the chrysolaminarin accumulated earlier. A maximum chrysolaminarin content of $64.86 \%$ DW was obtained in the low nitrogen cultures (Figure 6d). These results indicated that chrysolaminarin acts as storage products in O. aurita, especially in nitrogen-depleted condition. Myklestad [31] also found that the chrysolaminarin contents of marine diatoms Chaetoceros affinis and Skeletonema costatum were usually low in the exponential phase of growth, but they increased very rapidly when nutrients were exhausted in the stationary phase. The light intensity also affects the content of glucan; at nutrient saturation, high light led to the higher level of chrysolaminarin, which was consistent with the results in this study.

However, nutrient depletion also limited the growth of $O$. aurita, leading to the decline of biomass concentration (Figure 6a,b). Chrysolaminarin productivity, as a combined effect of biomass concentration and chrysolaminarin content, was a more suitable evaluation index for chrysolaminarin production. The chrysolaminarin volumetric productivity of $O$. aurita cultivated under different conditions was compared (Table 2). High light (HL) was demonstrated to be beneficial for maximizing chrysolaminarin productivity, as the biomass concentration and chrysolaminarin content of $O$. aurita under HL were significantly higher than their counterparts under low light (LL). Under HL, because of the significant 
enhancement in biomass concentration, the obtained chrysolaminarin productivity in high nitrogen $(\mathrm{HN})$ was $14.18 \%$ higher than that in low nitrogen (LN), resulting in a record high chrysolaminarin productivity of $306 \mathrm{mg} \mathrm{L}^{-1}$ day $^{-1}$. The results indicated that the microalga, O. aurita, may be a promising natural source for the production of antioxidative chrysolaminarin.

Figure 6. The biomass $(\mathbf{a}, \mathbf{b})$ and chrysolaminarin content $(\mathbf{c}, \mathbf{d})$ of $O$. aurita cultivated in the column photobioreactor under $100(\mathbf{a}, \mathbf{c})$ and $300(\mathbf{b}, \mathbf{d}) \mu \mathrm{mol}$ photons $\mathrm{m}^{-2} \mathrm{~s}^{-1}$ with a replete $(18 \mathrm{mM})$ and deficient $(6 \mathrm{mM})$ nitrate supply. Values are the means $\pm \mathrm{SD}(n=3)$. When error bars cannot be seen, the error is less than the size of the symbol.
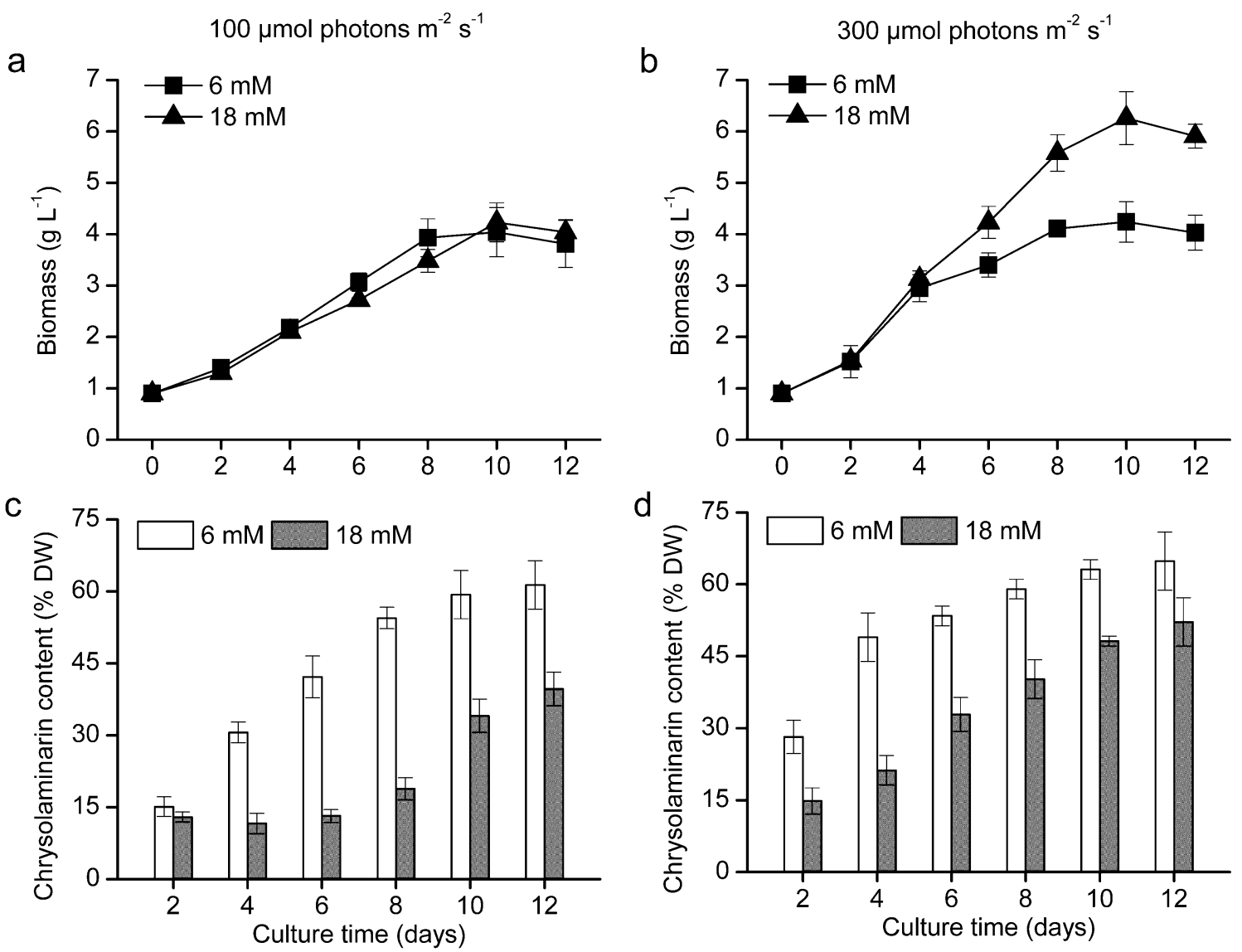

Table 2. The chrysolaminarin volumetric productivity of $O$. aurita cultivated under different conditions in a column photobioreactor at Day 10. Data represent the mean of three replicates.

\begin{tabular}{cccc}
\hline Culture Condition a $^{\text {a }}$ & $\begin{array}{c}\text { Biomass } \\
\text { Concentration }\left(\mathbf{g ~ L}^{-\mathbf{1}}\right)\end{array}$ & $\begin{array}{c}\text { Chrysolaminarin Content } \\
\text { (\% Dry Weight) }\end{array}$ & $\begin{array}{c}\text { Chrysolaminarin } \\
\text { Productivity (mg L }^{-\mathbf{1}} \mathbf{D a y}^{-\mathbf{1}} \mathbf{)}\end{array}$ \\
\hline LL + LN & 4.04 & 59.33 & 240 \\
LL + HN & 4.23 & 34.05 & 144 \\
HL + LN & 4.24 & 63.11 & 268 \\
HL + HN & 6.36 & 48.16 & 306 \\
\hline
\end{tabular}

${ }^{a}$ LL: low light $\left(100 \mu \mathrm{mol}\right.$ photons $\left.\mathrm{m}^{-2} \mathrm{~s}^{-1}\right)$; HL: high light $\left(300 \mu \mathrm{mol}\right.$ photons $\left.\mathrm{m}^{-2} \mathrm{~s}^{-1}\right)$; LN: low nitrogen (6 mM); HN: high nitrogen (18 mM). 


\section{Experimental Section}

\subsection{Organism and Culture Conditions}

The diatom, Odontella aurita K-1251, was obtained from the Scandinavian Culture Collection of Algae and Protozoa (SCCAP) at the University of Copenhagen (Copenhagen, Denmark) and deposited in our laboratory with modified L1 medium. The influences of nitrogen concentration and light intensity on chrysolaminarin accumulation were conducted with column photobioreactors $(60 \mathrm{~cm}$ length, $3 \mathrm{~cm}$ diameter). Cultures were aerated with air supplemented with $1 \% \mathrm{CO}_{2}$ through a hollow glass rod and maintained at $25 \pm 2{ }^{\circ} \mathrm{C}$ in an air-conditioned room. The growth medium recipe and cultural systems have been illustrated in our previous papers [5,15]. Two light intensities (100 and $300 \mu \mathrm{mol}$ photons $\mathrm{m}^{-2} \mathrm{~s}^{-1}$ ) and two nitrogen concentrations (6 and $18 \mathrm{mM}$ ) were designed for investigating the accumulation pattern of chrysolaminarin in O. aurita. The paste of algal cells collected by centrifugation was inoculated into different treatments at roughly the same starting cell concentration based on the optical density at a 750-nm wavelength. The cultures were harvested every two days, and the corresponding biomass concentration and chrysolaminarin content were determined.

\subsection{Biomass Measurement}

Briefly, 10-mL cultures were filtered onto a pre-weighed GF/B filter paper and dried at $105{ }^{\circ} \mathrm{C}$. The biomass concentration was determined by the difference in weight [15].

\subsection{Determination of Chrysolaminarin Content}

Chrysolaminarin was extracted from $O$. aurita according to Granum and Myklestad [32] with minor modification. Briefly, freeze-dried algal powder $(50 \mathrm{mg})$ was extracted with $5 \mathrm{~mL}$ of $50 \mathrm{mM}$ sulfuric acid at $60{ }^{\circ} \mathrm{C}$ for $30 \mathrm{~min}$. The extract was assayed quantitatively for chrysolaminarin content using the phenol-sulfuric acid method [33]. Briefly, $1 \mathrm{~mL}$ of chrysolaminarin extract was mixed with

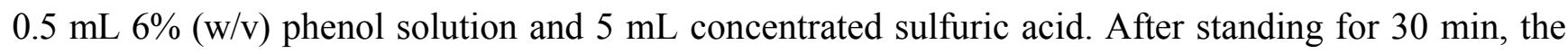
absorbance of the mixture at $490 \mathrm{~nm}$ was measured, and the chrysolaminarin content was determined by comparison to a calibration curve prepared with glucose.

\subsection{Preparation of Chrysolaminarin}

The isolation and purification procedure of chrysolaminarin from $O$. aurita was performed according to the flowchart shown in Figure 7. Freeze-dried microalgal powder $(10 \mathrm{~g})$ was extracted twice with $500 \mathrm{~mL}$ sulfuric acid $(50 \mathrm{mM})$ in a $60{ }^{\circ} \mathrm{C}$ water bath for $30 \mathrm{~min}$. The supernatants were collected by centrifugation and precipitated with four volumes of $95 \%$ ethanol at $4{ }^{\circ} \mathrm{C}$. The precipitate was recovered by centrifugation ( $5000 \mathrm{rpm}, 5 \mathrm{~min}$ ) and washed twice with ethanol and acetone, then freeze-dried. The freeze-dried extracts were dissolved in deionized water, and the proteins were removed by the mixture of chloroform: $n$-butyl alcohol (4:1, v/v) according to the Sevag method [34]. The deproteinized solution was dialyzed against deionized water for $48 \mathrm{~h}$, and the crude chrysolaminarin was obtained under freeze drying. Then, $3 \mathrm{~mL}$ of crude chrysolaminarin solution $\left(10 \mathrm{~g} \mathrm{~L}^{-1}\right)$ were applied to a DEAE-52 cellulose chromatography column $(2 \times 30 \mathrm{~cm})$ and gradient 
eluted with sodium chloride $(0.1 \mathrm{M}, 0.3 \mathrm{M}$ and $0.5 \mathrm{M})$. Each $5 \mathrm{~mL}$ of eluate was collected at a flow rate of $0.5 \mathrm{~mL} / \mathrm{min}$ and monitored for the presence of polysaccharides using the phenol-sulfuric acid method [33]. The collected fraction (named CL1) was dialyzed, concentrated and loaded on a Sephadex G-200 column (Pharmacia, Uppsala, Sweden) with 0.1 M sodium chloride as the mobile phase. Each $2 \mathrm{~mL}$ of eluate was collected at a flow rate of $0.2 \mathrm{~mL} / \mathrm{min}$. The corresponding chrysolaminarin fraction was collected, dialyzed against distilled water for $48 \mathrm{~h}$ and concentrated with air flow. Freeze drying of the resulting solution obtained the chrysolaminarin as a faintly white powder (named CL2) and gave the chrysolaminarin in a 10\% yield, which was used for gas chromatography-mass spectrometry (GC-MS), infrared spectroscopy (IR) and nuclear magnetic resonance spectroscopy (NMR).

Figure 7. Isolation and purification procedure of chrysolaminarin from $O$. aurita.

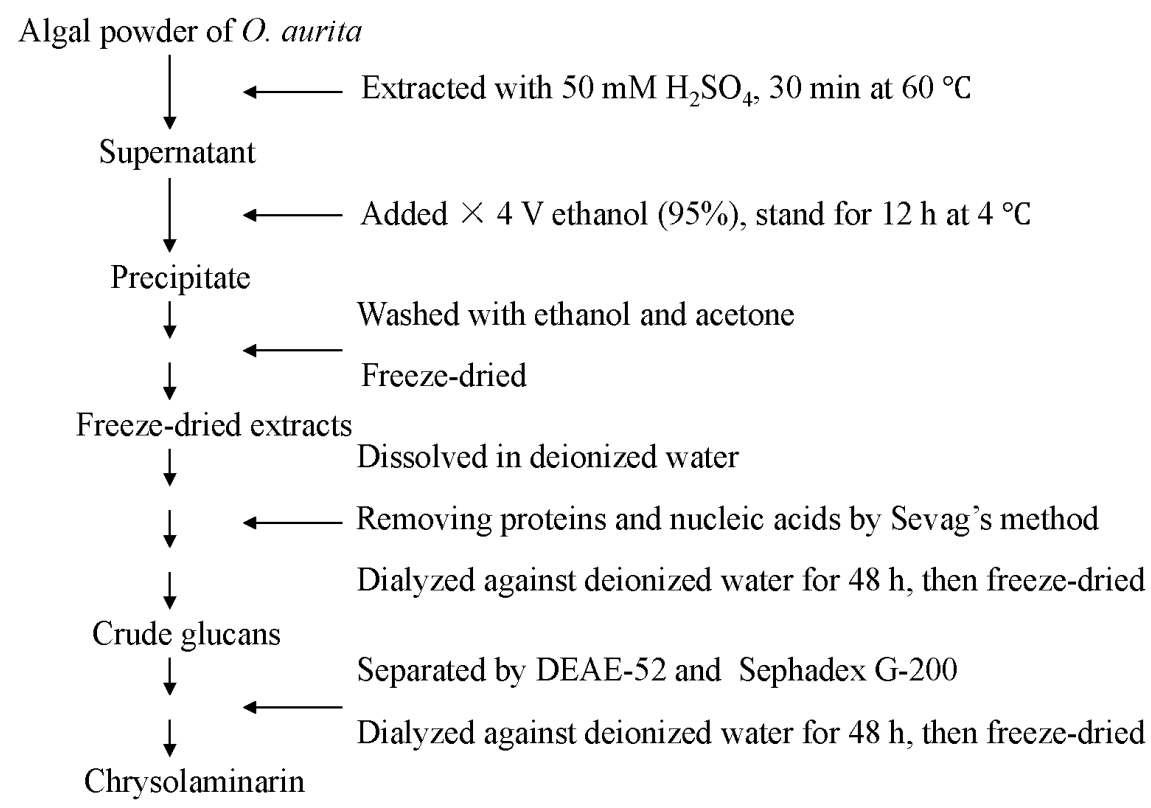

\subsection{Structural Analysis}

\subsubsection{Molecular Weight}

The average molecular weight of chrysolaminarin CL2 was determined by comparison to a calibration curve prepared with the T-series Dextran standards (Sigma-Aldrich, ST, Louis, MO, USA) as molecular mass markers using gel-filtration chromatography (GPC) [35].

\subsubsection{Monosaccharide Composition}

GC-MS (TRACE, Thermo Finnigan, Waltham, MA, USA) was used for analysis of the monosaccharide components. The chrysolaminarin, CL2 $(10 \mathrm{mg})$, was hydrolyzed in $10 \mathrm{~mL} 3 \mathrm{M}$ trifluoroacetic acid (TFA) at $105{ }^{\circ} \mathrm{C}$ for $6 \mathrm{~h}$. The product was reduced with $\mathrm{NaBH}_{4}$ for $2 \mathrm{~h}$ at room temperature, acetic anhydride at $100{ }^{\circ} \mathrm{C}$ for $2 \mathrm{~h}$ and then analyzed by gas chromatography at a temperature program of $150-220^{\circ} \mathrm{C}$ with a rate of $4{ }^{\circ} \mathrm{C} / \mathrm{min}$ using $\mathrm{N}_{2}$ as the carrier. A standard curve was set up with standard monosaccharides derivatized and measured under the same procedure [10]. 


\subsubsection{IR Spectroscopy}

The chrysolaminarin, CL2, was ground with dry $\mathrm{KBr}$ powder and pressed for Fourier transform infrared (FTIR) measurement using an EQUINOX55 spectrometer (Bruker, Bremen, Germany) at the frequency range of $4000-400 \mathrm{~cm}^{-1}$.

\subsubsection{NMR Analysis}

Dried chrysolaminarin CL2 (15 mg) was dissolved in $\mathrm{D}_{2} \mathrm{O}$ for NMR measurements. NMR spectra were obtained on a Bruker AVANCE III 500 spectrometer (Bruker Biospin, Rheinstetten, Germany) and recorded at $500.26 \mathrm{MHz}$ for ${ }^{1} \mathrm{H}$ and 125.8 for ${ }^{13} \mathrm{C}$ nuclei, using a 5 -mm broadband probe head. Spectra were obtained at $298 \mathrm{~K}$ in $\mathrm{D}_{2} \mathrm{O}$, with DSS as the internal reference standard. The signals were assigned regarding Størseth et al. [6].

\subsection{Antioxidant Activity Assessment}

\subsubsection{Reducing Power}

The reducing power of chrysolaminarin CL2 was determined based on Deng et al. [10] with minor modification. Briefly, $1 \mathrm{~mL}$ of chrysolaminarin CL2 solution was mixed with $0.2 \mathrm{~mL} 2 \mathrm{M}$ sodium phosphate buffer ( $\mathrm{pH} 6.6)$ and $0.5 \mathrm{~mL} 1 \%(\mathrm{w} / \mathrm{v})$ aqueous potassium ferricyanide. The mixture was incubated at $50{ }^{\circ} \mathrm{C}$ for $20 \mathrm{~min}$ in a water bath. Then, $2.5 \mathrm{~mL} 10 \%(\mathrm{w} / \mathrm{v})$ of trichloroacetic acid were added to the mixture. The resultant mixture was centrifuged at $3500 \mathrm{rpm}$ for $10 \mathrm{~min}$. Two milliliters of the supernatant were diluted with $3 \mathrm{~mL}$ distilled water and then mixed with $0.5 \mathrm{~mL} 0.3 \%$ (w/v) ferric chloride. The absorbance was measured at $700 \mathrm{~nm}$ against distilled water. The increase in absorbance indicated an increase in reducing power.

\subsubsection{DPPH Radical Scavenging Activity}

The scavenging activity of 1,1-diphenyl-2-picrylhydrazyl (DPPH) radical was carried out according to Sachindra et al. [36]. Briefly, $2 \mathrm{~mL} 0.16 \mathrm{mM}$ ethanolic DPPH solution was added to $2 \mathrm{~mL}$ of related solution. The mixture was shaken vigorously and left to stand for $30 \mathrm{~min}$ at room temperature in the dark, and then, the absorbance was measured at $517 \mathrm{~nm}$. The inhibition of DPPH radicals by the samples was calculated as follows: DPPH radical scavenging activity $(\%)=[1-($ absorbance of sample - absorbance of blank $) /$ absorbance of control $)] \times 100 \%$.

\subsubsection{Hydroxyl Radical Scavenging Activity}

Hydroxyl radical scavenging activity was determined based on Yang et al. [2] with minor modification. Briefly, $0.2 \mathrm{~mL}$ of chrysolaminarin CL2 solution were mixed with $2 \mathrm{~mL}$ EDTA-Fe solution $(0.15 \mathrm{mM})$ and $0.8 \mathrm{~mL}$ salicylic acid $(2 \mathrm{mM})$. Afterwards, $2 \mathrm{~mL} \mathrm{H}_{2} \mathrm{O}_{2}(6 \mathrm{mM})$ were added to the reaction mixture and incubated for $30 \mathrm{~min}$ at $37{ }^{\circ} \mathrm{C}$. Absorbance was measured at $510 \mathrm{~nm}$. The capability of hydroxyl radical scavenging by the samples was calculated as follows: hydroxyl radical scavenging activity $(\%)=[1-($ absorbance of sample - absorbance of blank $) /$ Abs. of control $)] \times 100 \%$. 


\section{Conclusions}

The new chrysolaminarin, CL2, was purified from marine diatom, O. aurita, and structurally determined as a glucan linked by the $\beta$-D- $(1 \rightarrow 3)$ (main chain) and $\beta$-D- $(1 \rightarrow 6)$ (side chain) glycosidic bond. The results of antioxidant experiments indicate that CL2 possesses potent antioxidant, especially for scavenging hydroxyl radicals. The high volumetric productivity of chrysolaminarin in the column photobioreactor suggests that the microalga $O$. aurita could be developed as a new natural source of antioxidant or as a food supplement.

\section{Acknowledgments}

The research was supported by the following funding: the Special Program for Low-Carbon, Reform and Development Commission of Guangdong Province; the Natural Science Foundation of China (No. 31170337 and No. 41176105); the National High Technology Research and Development Program of China (863 Program) (No. 2013AA065805); the National Basic Research Program of China (973 Program) (No. 2011CB2009001); the Key Science and Technology Innovation Project of Jiangxi Provincial Department of Science and Technology (No. 20124ACB01200); the Knowledge Innovation Team Project of Jiangxi Province (20113BCB24017); the National Natural Science Foundation of China (No. 41263006).

\section{Author Contributions}

Conceived of and designed the experiments: Chengwu Zhang and Aifen Li. Performed the experiments: Song Xia and Baoyan Gao. Analyzed the data: Song Xia, Jihai Xiong and Ziqiang Ao. Wrote and revised the paper: Song Xia, Baoyan Gao and Chengwu Zhang.

\section{Conflicts of Interest}

The authors declare no conflict of interest.

\section{References}

1. Finkel, T.; Holbrook, N.J. Oxidants, oxidative stress and the biology of aging. Nature 2000, 408, 239-247.

2. Yang, X.; Wang, R.; Zhang, S.; Zhu, W.; Tang, J.; Liu, J.; Chen, P.; Zhang, D.; Ye, W.; Zheng, Y.; et al. Polysaccharides from Panax japonicus C.A. Meyer and their antioxidant activities. Carbohydr. Polym. 2014, 101, 386-391.

3. Zhang, Z.S.; Wang, X.M.; Mo, X.F.; Qi, H.M. Degradation and the antioxidant activity of polysaccharide from Enteromorpha linza. Carbohydr. Polym. 2013, 92, 2084-2087.

4. Sarkar, R.; Nandan, C.K.; Bhunia, S.K.; Maiti, S.; Maiti, T.K.; Sikdar, S.R.; Islam, S.S. Glucans from alkaline extract of a hybrid mushroom (backcross mating between PfloVv12 and Volvariella volvacea): Structural characterization and study of immunoenhancing and antioxidant properties. Carbohydr. Res. 2012, 347, 107-113. 
5. Xia, S.; Li, A.F.; Wan, L.L.; Sang, M.; Zhang, C.W. Effects of nutrients and light intensity on the growth and biochemical composition of a marine microalga Odontella aurita. Chin. J. Oceanol. Limnol. 2013, 31, 1163-1173.

6. Størseth, T.R.; Kirkvold, S.; Skjermo, J.; Reitan, K.I. A branched $\beta$-D-( $1 \rightarrow 3,1 \rightarrow 6)$-glucan from the marine diatom Chaetoceros debilis (Bacillariophyceae) characterized by NMR. Carbohydr. Res. 2006, 341, 2108-2114.

7. Muramatsu, D.; Iwai, A.; Aoki, S.; Uchiyama, H.; Kawata, K.; Nakayama, Y.; Nikawa, Y.; Kusano, K.; Okabe, M.; Miyazaki, T.; et al. $\beta$-glucan derived from Aureobasidium pullulans is effective for the prevention of influenza in mice. PLoS One 2012, 7, e41399.

8. Ahmad, A.; Anjum, F.M.; Zahoor, T.; Nawaz, H.; Dilshad, S.M. Beta glucan: A valuable functional ingredient in foods. Crit. Rev. Food Sci. Nutr. 2012, 52, 201-212.

9. Bhanja, S.K.; Nandan, C.K.; Mandal, S.; Bhunia, B.; Maiti, T.K.; Mondal, S.; Islam, S.S. Isolation and characterization of the immunostimulating $\beta$-glucans of an edible mushroom Termitomyces robustus var. Carbohydr. Res. 2012, 357, 83-89.

10. Deng, C.; Hu, Z.; Fu, H.; Hu, M.; Xu, X.; Chen, J. Chemical analysis and antioxidant activity in vitro of a $\beta$-D-glucan isolated from Dictyophora indusiata. Int. J. Biol. Macromol. 2012, 51, 70-75.

11. Braud, J.P. Simultaneous culture in pilot tanks of the macroalga Chondrus crispus (Gigartinaceae) and the microalga Odontella aurita (Eupodiscaceae) producing EPA. In Marine Microorganisms for Industry; Le Gal, Y., Muller-Feuga, A., Eds.; Ifremer Edition: Plouzane, France, 1998; pp. 39-47.

12. Mimouni, V.; Ulmann, L.; Pasquet, V.; Mathieu, M.; Picot, L.; Bougaran, G.; Cadoret, J.P.; Morant-Manceau, A.; Schoefs, B. The potential of microalgae for the production of bioactive molecules of pharmaceutical interest. Curr. Pharm. Biotechnol. 2012, 13, 2733-2750.

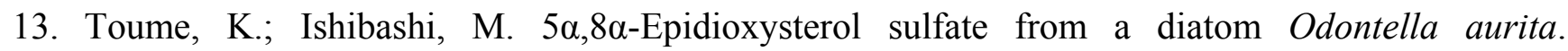
Phytochemistry 2002, 61, 359-360.

14. Moreau, D.; Tomasoni, C.; Cathrine, J.; Kaas, R.; Guedes, L.; Cadoret, J.P.; Muller-Feuga, A.; Kontiza, I.; Vagias, C.; Roussis, V.; et al. Cultivated microalgae and the carotenoid fucoxanthin from Odontella aurita as potent anti-proliferative agents in bronchopulmonary and epithelial cell lines. Environ. Toxicol. Pharmacol. 2006, 22, 97-103.

15. Xia, S.; Wang, K.; Wan, L.L.; Li, A.F.; Hu, Q.; Zhang, C.W. Production, characterization, and antioxidant activity of fucoxanthin from the marine diatom Odontella aurita. Mar. Drugs 2013, 11, 2667-2681.

16. Wang, R.; Chen, P.; Jia, F.; Tang, J.; Ma, F. Optimization of polysaccharides from Panax japonicus C.A. Meyer by RSM and its anti-oxidant activity. Int. J. Biol. Macromol. 2012, 50, 331-336.

17. You, Q.H.; Yin, X.L.; Zhang, S.N.; Jiang, Z.H. Extraction, purification, and antioxidant activities of polysaccharides from Tricholoma mongolicum Imai. Carbohydr. Polym. 2014, 99, 1-10.

18. Zou, C.; Du, Y.; Li, Y.; Yang, J.; Zhang, L. Preparation and in vitro antioxidant activity of lacquer polysaccharides with low molecular weights and their sulfated derivatives. Int. J. Biol. Macromol. 2010, 46, 140-144.

19. Ding, X.; Tang, J.; Cao, M.; Guo, C.X.; Zhang, X.; Zhong, J.; Zhang, J.; Sun, Q.; Feng, S.; Yang, Z.R.; et al. Structure elucidation and antioxidant activity of a novel polysaccharide isolated from Tricholoma matsutake. Int. J. Biol. Macromol. 2010, 47, 271-275. 
20. Zhang, Y.X.; Dai, L.; Kong, X.W.; Chen, L.W. Characterization and in vitro antioxidant activities of polysaccharides from Pleurotus ostreatus. Int. J. Biol. Macromol. 2012, 51, 259-265.

21. Hirokawa, Y.; Fujiwara, S.; Suzuki, M.; Akiyama, T.; Sakamoto, M.; Kobayashi, S.; Tsuzuki, M. Structural and physiological studies on the storage $\beta$-polyglucan of haptophyte Pleurochrysis haptonemofera. Planta 2008, 227, 589-599.

22. Choi, J.I.; Kim, H.J.; Lee, J.W. Structural feature and antioxidant activity of low molecular weight laminarin degraded by gamma irradiation. Food Chem. 2011, 129, 520-523.

23. Størseth, T.R.; Hansen, K.; Skjermo, J.; Krane, J. Characterization of a $\beta$-D- $(1 \rightarrow 3)$-glucan from the marine diatom Chaetoceros mülleri by high-resolution magic-angle spinning NMR spectroscopy on whole algal cells. Carbohydr. Res. 2004, 339, 421-424.

24. Kozarski, M.; Klaus, A.; Niksic, M.; Vrvic, M.M.; Todorovic, N.; Jakovljevic, D.; van Griensven, L.J.L.D. Antioxidative activities and chemical characterization of polysaccharide extracts from the widely used mushrooms Ganoderma applanatum, Ganoderma lucidum, Lentinus edodes and Trametes versicolor. J. Food Compos. Anal. 2012, 26, 144-153.

25. Lo, T.C.-T.; Chang, C.A.; Chiuc, K.-H.; Tsayd, P.-K.; Jena, J.-F. Correlation evaluation of antioxidant properties on the monosaccharide components and glycosyl linkages of polysaccharide with different measuring methods. Carbohydr. Polym. 2011, 86, 320-327.

26. Kanmani, P.; Kumar, R.S.; Yuvaraj, N.; Paari, K.A.; Pattukumar, V.; Arul, V. Production and purification of a novel exopolysaccharide from lactic acid bacterium Streptococcus phocae PI80 and its functinoal characteristics activity invitro. Bioresour. Technol. 2011, 102, 4827-4833.

27. Ker, Y.-B.; Chen, K.-C.; Chyau, C.-C.; Chen, C.-C.; Guo, J.-H.; Hsien, C.-L.; Wang, H.-E.; Peng, C.-C.; Chang, C.-H.; Peng, R.-P.; et al. Antioxidant capability of polysaccharides fractionated from submerge-cultured Agaricus blazei Mycelia. J. Agric. Food Chem. 2005, 53, 7052-7058.

28. Li, J.; Liu, Y.; Fan, L.; Ai, L.; Shan, L. Antioxidant activities of polysaccharides from the fruiting bodies of Zizyphus jujuba cv. Jinsixiaozao. Carbohydr. Polym. 2011, 84, 390-394.

29. Goiris, K.; Muylaert, K.; Fraeye, I.; Foubert, I.; Brabanter, J.D.; Cooman, L.D. Antioxidant potential of microalgae in relation to their phenolic and carotenoid content. J. Appl. Phycol. 2012, 24, 1477-1486.

30. Guedes, A.C.; Giao, M.S.; Seabra, R.; Ferreira, A.C.S.; Tamagnini, P.; Moradas-Ferreira, P.; Malcata, F.X. Evaluation of the antioxidant activity of cell extracts from microalgae. Mar. Drugs 2013, 11, 1256-1270.

31. Myklestad, S.M. Production, chemical structure, metabolism, and biological function of the $(1 \rightarrow 3)$-linked, $\beta$-D-glucans in diatoms. Biol. Oceanogr. 1989, 6, 313-326.

32. Granum, E.; Myklestad, S.M. A simple combined method for determination of $\beta$-1,3-glucan and cell wall polysaccharides in diatoms. Hydrobiologia 2002, 477, 155-161.

33. Dubois, M.; Gillies, K.A.; Hamilton, J.K.; Rebers, P.A.; Smith, F. Colorimetric method for the determination of sugars and related substances. Anal. Chem. 1956, 28, 350-356.

34. Sevag, M.G.; Lackman, D.B.; Smolens, J. The isolation of the components of streptococcal nucleoproteins in serologically active form. J. Biol. Chem. 1938, 124, 425-436.

35. Ye, M.; Chen, W.X.; Qiu, T.; Yuan, R.Y.; Ye, Y.W.; Cai, J.M. Structural characterization and anti-ageing activity of extracellular polysaccharide from a strain of Lachnum sp. Food Chem. 2012, 132, 338-343. 
36. Sachindra, N.M.; Sato, E.; Maeda, H.; Hosokawa, M.; Niwano, Y.; Kohno, M.; Miyashita, K. Radical scavenging and singlet oxygen quenching activity of marine carotenoid fucoxanthin and its metabolites. J. Agric. Food Chem. 2007, 55, 8516-8522.

(C) 2014 by the authors; licensee MDPI, Basel, Switzerland. This article is an open access article distributed under the terms and conditions of the Creative Commons Attribution license (http://creativecommons.org/licenses/by/3.0/). 